\title{
THE STABILITY MONITORING OF THE MANUFACTURING PROCESS OF ELECTRICAL INSULATING SYSTEMS OF TRACTION ELECTRIC MACHINES
}

\begin{abstract}
Introduction. Electrical insulation systems make up about $0.03 \%$ of the traction electric machines (TEM) mass, but they are of exceptional importance and affect the design capabilities and manufacturing techniques of electric machines, ultimately on their specific weight and overall dimensions, on the reliability and durability of the TEM. Purpose. The monitoring of the stability of the manufacturing process of electrical insulating systems of the TEM based on the insulation resistance measurements. Methodology. The analysis of the manufacturing process is carried out for three versions of the case of insulation of the magnetic system of the DC traction electric motor. Practical value. Construction and analysis of special graphs (charts) of individual values and cumulative sums of insulation resistance, sliding range MR allow to find out whether the technological process of manufacturing electric insulating systems of traction electric machines is in a statistically controllable state. References 11, tables 1, figures 4.
\end{abstract}

Key words: traction electrical machines, electrical insulation systems, insulation resistance, cumulative sum control chart, manufacturing process stability.

Показано, что сопротивление изоляции может служить информативным параметром стабильности технологического процесса изготовления электроизоляционных систем тяговых электрических машин. Установлено, что сопротивление изоляции находится в пределах $\pm 3 \sigma$ относительно среднего значения каждой выборки трех вариантов исполнения электроизоляционной системы. Представлены контрольные карты индивидуальных значений и кумулятивных сумм сопротивления изоляции магнитной системы тяговых электродвигателей постоянного тока. Библ. 8 , табл. 1 , рис. 4.

Ключевые слова: тяговые электрические машины, электроизоляционные системы, сопротивление изоляции, контрольные карты кумулятивных сумм, стабильность технологического процесса.

Introduction. Electrical insulation systems make up about $0.03 \%$ of the mass of traction electric machines (TEM) but they have an exceptional importance and influence the possibilities of design solutions and the technology of manufacturing electric machines, as a result - on their specific weight and overall dimensions, for reliability and durability of TEM. Improvement of electrical insulating composite systems of TEM is carried out by creating new, more progressive materials and technological processes [1].

Insulation resistance is an integral indicator of manufacturing process stability. Monitoring of product quality in the process of its production is always acute for producers. In modern production conditions, methods and procedures based on statistical analysis of product characteristics are used [2-4]. Quantitatively, the accuracy of manufacturing processes is estimated using the coefficient

$$
K_{T}=\frac{6 \sigma}{T},
$$

where $T=T_{u p}-T_{\text {lower }}$ is the tolerance of the product to the controlled parameter (the difference between the upper and lower values), $\sigma$ is the standard quadratic deviation of the controlled quantity.

The accuracy of the manufacturing process is assessed based on the following criteria:

- at $K_{T} \leq 0.75$ - the manufacturing technological process is accurate;

- at $K_{T}=(0.75-0.98)$ - it requires close observation;

- at $K_{T}>0.98$ - unsatisfactory.

The criterion for assessing the state of electrical insulating systems in production is the value of insulation resistance $R_{\text {ins }}$. This value is indicated in the normative and technical documentation [5]. Thus, for high-voltage electrical insulation systems of TEM, the insulation resistance $R_{\text {ins }}$ relative to the housing (the lower threshold value) must be at least $20 \mathrm{M} \Omega$ in the cold state for machines with rated voltage above $400 \mathrm{~V}$. The upper value of the insulation resistance is not regulated. Resistance of insulation is an integral statistical characteristic, which depends, first of all, on the electrophysical properties of the composite system, and the technological process of manufacturing assembly units and the TEM itself. It should be noted that the peculiarity of the technological process of manufacturing TEM insulating systems is a high level of nonmechanized (manual) production.

The goal of the paper is monitoring of the stability of the technological process for the manufacture of electrical insulating systems of TEM based on the insulation resistance measurements in the production.

Monitoring the stability of the manufacturing process by control charts of individual values. The analysis of the manufacturing process is carried out for three versions of the case insulation of the magnetic system of the DC traction electric motor. In each of the three versions of the housing insulation - by 12 samples each differing in the number of layers and the type of insulation tapes. Insulation resistance measurements were made with a MI 2077 teraohmmeter at constant voltage of $2500 \mathrm{~V}$.

Fig. 1, $a$ presents the results of measurements, Fig. $1, b$ - statistical characteristics of the insulation resistance of the three versions of the housing insulation. The statistical spread of the measured insulation resistance values (Fig. 1,b) within each version of the insulation system is associated with at least two reasons [6]. The 
first one is due to unavoidable random measurement errors and the impossibility of absolutely accurate reproduction of test conditions. The second reason is deeper and consists in the fact that the insulation resistance reflects the existing structural and technological defects in the insulation system, and is associated with unhomogeneous insulation material, technological equipment, personnel qualification.
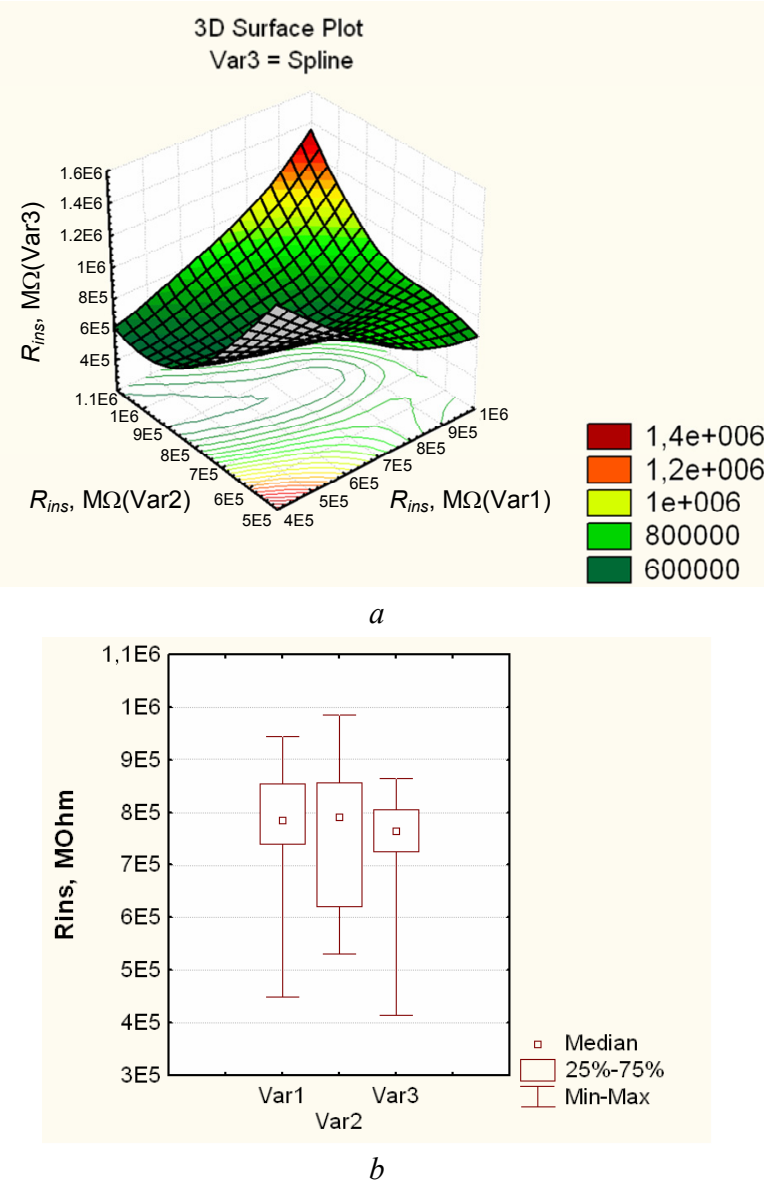

Fig. 1. Samples of insulation resistance of three versions of the housing insulation system

For all three options, the insulation resistance is within $\pm 3 \sigma$ of the nominal (mean) value for each sample (Fig. 2), which corresponds to the concept of «Six Sigma» [7]

In the production process, one of the main monitoring tools is the control charts (or Shewhart control charts) that visualize the statistical characteristics of the manufacturing process under investigation $[4,8]$. Control charts of individual quantities (Fig. 3) allow to detect deviations $(X)$ or sliding range $(M R)$ of insulation resistance which are due to non-accidental reasons.

When using maps of individual values, the control limits are calculated on the basis of a measure of variation obtained from the sliding ranges of two observations. The sliding range $(M R)$ is the absolute value of the measurement difference in consecutive pairs (the difference between the first and second measurements, the second and third ones, etc.).

On the basis of sliding ranges, the average sliding range is calculated, which is used to build control charts.
The lower and upper boundaries on the chart (Fig. 3, dotdash lines) are at a distance of $3 * \sigma$ from the mean (central line). Here, there are no systematic shifts (trends), nor any other signs of the process exit from control: the points of both charts fluctuate evenly (based on visual analysis) relative to the corresponding midlines. The points on both control charts are inside the control limits. The value of the second measurement is close enough to the lower control limit, but against the background of a general positive picture this is not an alarming event.

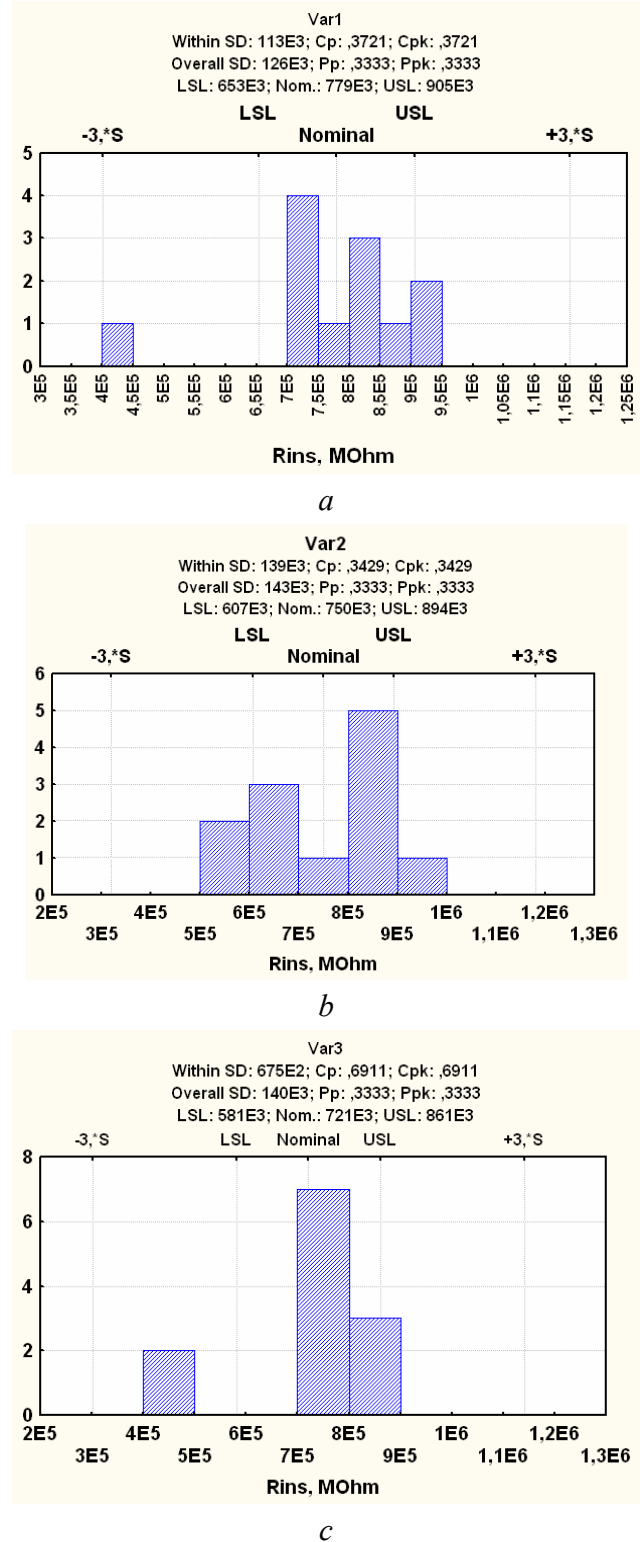

Fig. 2. On homogeneity of insulation resistance samples

To specify the criteria for finding a series of points, the area of the individual control chart above the central line and below it is divided into three «zones»: A, B and $\mathrm{C}$ [4]. By default, zone $\mathrm{A}$ is defined as a region located at distance from $2^{*} \sigma$ to $3^{*} \sigma$ on either side of the center line. Zone $\mathrm{B}$ is a region spaced from the central line at a distance from $1^{*} \sigma$ to $2^{*} \sigma$, and the zone $\mathrm{C}$ is the region located between the central line on both sides of it and bounded by a straight line drawn $1^{*} \sigma$ away from the central line. 


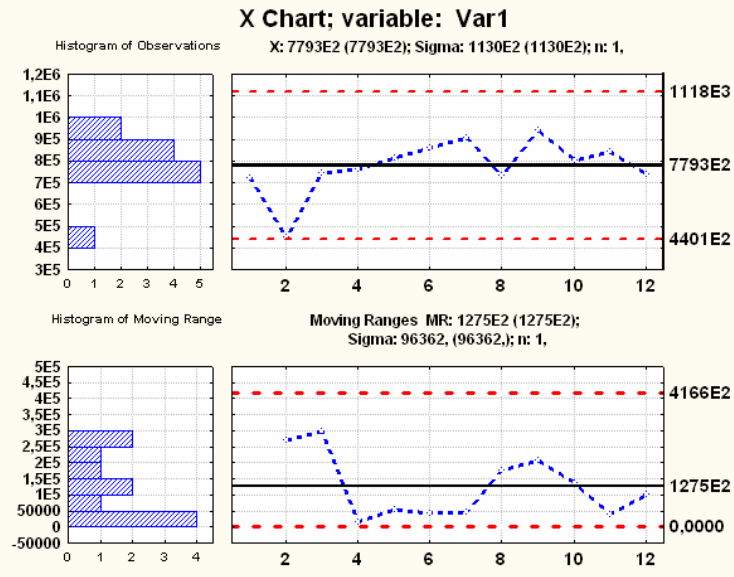

Fig. 3. A control chart of individual values of insulation resistance and sliding ranges for version 1 of the housing insulation system

Depending on the number of points and their location in one of the zones of the control chart, seven criteria are established.

When a criterion is fulfilled in the table of testing results, the row corresponding to this criterion is highlighted in red, and instead of $O K$ in the columns, the numbers of points that fall into the risk zone are indicated (Table 1).

The results of testing (Table 1) performed for the $M R$ - control chart (Fig. 3) and for the other two versions of the housing insulation show that under all criteria of testing the manufacturing process by insulation resistance, the investigated indicators are in statistically controllable state. There was no signal about the need to take precautionary measures.

Table 1

Stability test results for the manufacturing process

\begin{tabular}{|l|c|c|}
\hline \multirow{2}{*}{ Zones A/B/C: $(3.0 / 2.0 / 1.0)^{*} \sigma$} & \multicolumn{2}{|c|}{$\begin{array}{c}\text { Variable var1 } \\
\text { MR-chart } \\
\text { Central line } \\
127545.45 \mathrm{M} \Omega, \\
\sigma=96361.95 \mathrm{M} \Omega\end{array}$} \\
\cline { 2 - 3 } & $\begin{array}{c}\text { from the } \\
\text { sample }\end{array}$ & $\begin{array}{c}\text { to the } \\
\text { sample }\end{array}$ \\
\hline $\begin{array}{l}9 \text { points on one side of } \\
\text { the central line }\end{array}$ & OK & OK \\
\hline 6 points of growth / decrease & OK & OK \\
\hline $\begin{array}{l}14 \text { points alternate upwards } \\
\text { and down }\end{array}$ & OK & OK \\
\hline $\begin{array}{l}2 \text { out of 3 points in zone A or } \\
\text { outside }\end{array}$ & OK & OK \\
\hline $\begin{array}{l}4 \text { out of } 5 \text { points in zone B or } \\
\text { outside }\end{array}$ & OK & OK \\
\hline 15 points in zone C & OK & OK \\
\hline 8 points outside zone C & OK & OK \\
\hline
\end{tabular}

The control charts of cumulative sums (CuSum) [4] (Fig. 4) which represent the accumulated sums of deviations of individual values of the observed variable (insulation resistance) from the mean value have greater sensitivity to process disturbances.

Fig. 4 shows the control charts of cumulative (accumulated) sums for three versions of housing insulation. For the twelfth CuSum observation (Fig. 4,c), the pass from the lower boundary is noted and for the eleventh - from the upper one for the $M R$ which can serve as a sign of the beginning of the manufacturing process disruption. Here, for this variant, the trend of sample values of CuSum also appears which requires clarification of the reasons for its appearance.
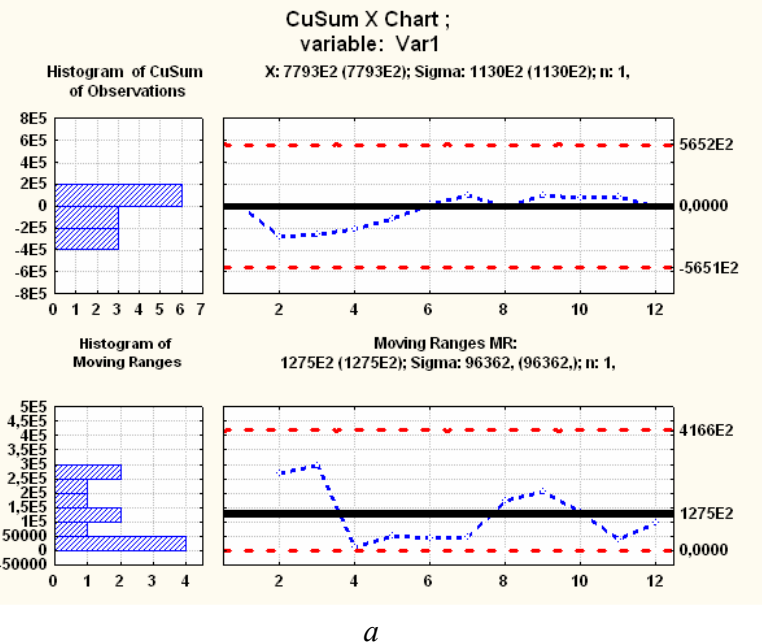

$a$

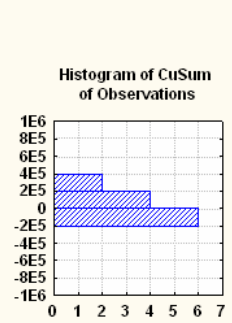

CuSum $X$ Chart;

variable: Var2

X: $7502 E 2$ (7502E2); Sigma: 1394E2 (1394E2); n: 1 ,

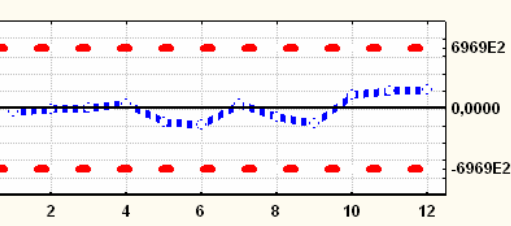

Histogram of

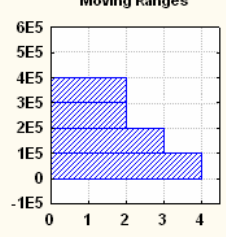

Moving Ranges MR: 1573E2 (1573E2)
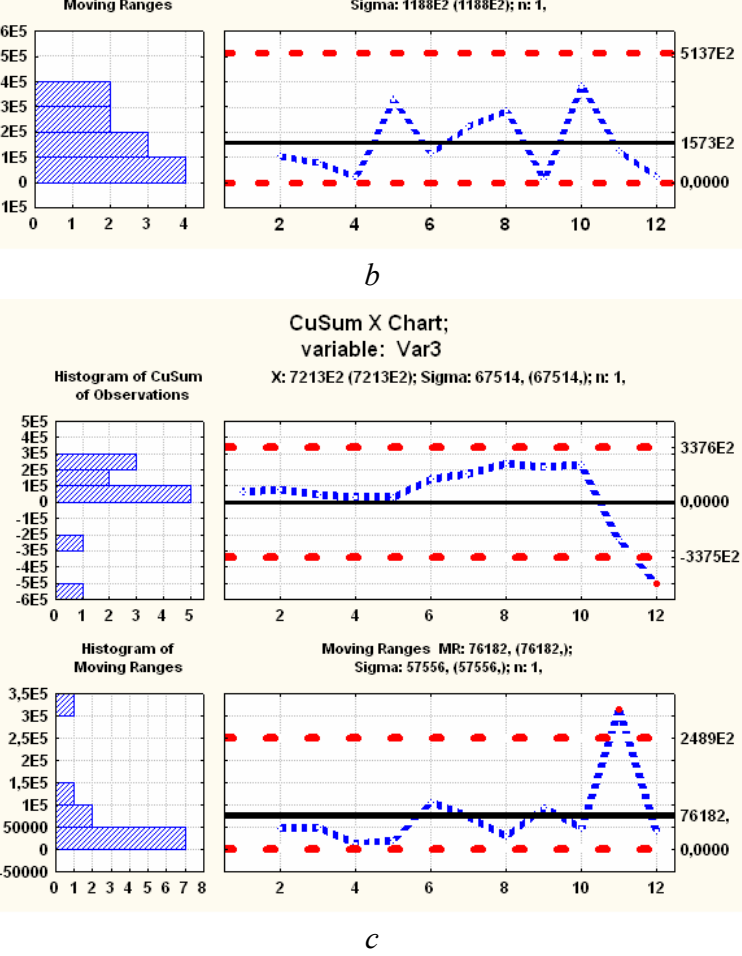

Fig. 4. Control charts of cumulative sums and sliding ranges of insulation resistance of three options of the casing insulation system 
Conclusions. Construction and analysis of special graphs (charts) of individual values and cumulative sums of insulation resistance, sliding range $M R$ allow to find out whether the technological process of manufacturing electric insulating systems of traction electric machines is in a statistically controllable state.

The presented monitoring procedure can be used to analyze the stability of technological processes for manufacturing electrical insulation systems of turbo and hydro generators.

\section{REFERENCES}

1. Ogonkov V.G., Serebryannikov S.V. Elektroizoliatsionnye materialy $i$ sistemy izoliatsii dlia elektricheskikh mashin. $V$ dvukh knigakh. Kn. 2 [Electrical insulation materials and insulation systems for electrical machines. In 2 books. Book 2]. Moscow, Publishing house MEI, 2012. 304 p. (Rus).

2. Hartman K., Letsky E., Shefer V. Planirovanie eksperimenta $v$ issledovanii tekhnologicheskikh protsessov [Planning an experiment in the study of technological processes]. Moscow, Mir Publ., 1977. 552 p.(Rus).

3. Draper N., Smith H. Prikladnoi regressionnyi analiz. Mnozhestvennaia regressiia. Applied Regression Analysis [Applied regression analysis. Multiple regression. Applied Regression Analysis. 3rd ed.]. Moscow, Dialectics Publ., 2007. 912 p. (Rus).

4. ISO 7870-4:2011. Cumulative sum charts - Guidance on quality control and data analysis using CUSUM techniques.

5. GOST 2582-2013. Mashiny elektricheskie vrashchaiushchiesia tiagovye. Obshchie tekhnicheskie usloviia
[State Standart 2582-2013. Electric rotating traction machines. General specifications]. Moscow, Standardinform Publ., 2014. 56 p. (Rus).

6. Bezprozvannych A.V., Moscvitin E.S. Double-kink number as an indicator of degree of cable paper ageing. Electrical engineering \& electromechanics, 2011, no.3, pp. 62-66. (Rus). doi: 10.20998/2074-272X.2011.3.16.

7. Eckes G. Six Sigma Team Dynamics: The Elusive Key to Project Success. Hoboken: John Wiley \&Sons, 2003. 262 p.

8. Zolotarev V.M., Antonets Yu.A., Gurin A.G., Shebenyuk L.A., Golik O.V. Investigation of the correlation of electrical and mechanical parameters of double insulation of enamel wires. Electrical engineering \& Electromechanics, 2005, no.2, pp. 78-80. (Rus).

Received 09.10.2017

G.V. Bezprozvannych ${ }^{1}$, Doctor of Technical Science, Professor, A.V. Roginskiy ${ }^{2}$, Postgraduate Student,

${ }^{1}$ National Technical University «Kharkiv Polytechnic Institute», 2, Kyrpychova Str., Kharkiv, 61002, Ukraine, phone +380 577076010 ,

e-mail: bezprozvannych@kpi.kharkov.ua

${ }^{2}$ SE Plant Electrotyazhmash,

299, Moskovsky Ave., Kharkiv, 61089, Ukraine, phone +380 505158552 49,

e-mail: roginskiy.av.@gmail.com

How to cite this article:

Bezprozvannych G.V., Roginskiy A.V. The stability monitoring of the manufacturing process of electrical insulating systems of traction electric machines. Electrical engineering \& electromechanics, 2017, no.6, pp. 65-68. doi: 10.20998/2074-272X.2017.6.10. 